\title{
Turismo de base comunitária na América Latina: uma estratégia em rede
}

\author{
Community-based tourism in Latin America: a networking strategy
}

\section{Turismo comunitario en América Latina: una estrategia en la red}

\author{
Edilaine Albertino de Moraes \\ Professora do Curso de Turismo da Universidade Federal de Juiz de Fora \\ Doutoranda em Psicossociologia de Comunidades e Ecologia Social pela \\ Universidade Federal do Rio de Janeiro \\ E-mail: edilaineturmoraes@hotmail.com \\ Marta de Azevedo Irving \\ Professora Titular da Universidade Federal do Rio de Janeiro \\ Doutora em Ciências pela Universidade de São Paulo \\ E-mail: marta.irving@mls.com.br \\ Teresa Cristina Miranda Mendonça \\ Professora Adjunta do Curso de Turismo da Universidade Federal Rural do Rio de Janeiro \\ Doutora em Ciências Sociais pela Universidade do Estado do Rio de Janeiro \\ E-mail: tecaturismo@yahoo.com.br
}

Data de Submissão: 04/03/2017 - Data de Aprovação: 16/10/2017

\begin{abstract}
Resumo: A abordagem sobre novas possibilidades para o desenvolvimento turístico, em várias regiões do mundo, passa pela compreensão do modo de construção de iniciativas designadas como turismo de base comunitária. Nesse contexto, este artigo tem o objetivo de interpretar algumas dessas experiências em curso na América Latina à luz da noção de redes. A metodologia adotada para orientar a reflexão proposta se baseou em pesquisa bibliográfica e documental acerca do tema, sendo complementada pelo levantamento de informações disponíveis nas páginas da internet de cada iniciativa identificada com esse foco e vinculada à Rede de Turismo Comunitário da América Latina (REDTURS). A sistematização dos dados se apoiou na elaboração de uma matriz síntese, tendo a sua interpretação sido desenvolvida por meio da adaptação da técnica de Análise de Conteúdo. Com base nos principais resultados da pesquisa, foi possível refletir que as redes de $T B C$ analisadas se configuram como um movimento de articulação de ações direcionadas, sobretudo, à comercialização no mercado de viagens e turismo, ao intercâmbio e ao compartilhamento de informações, à gestão e à operacionalização de empreendimentos, à influência em políticas públicas e ao fortalecimento de capacidades locais e de mobilização social, realizando alianças em escalas local, nacional e internacional. Palavras-chave: Turismo de base comunitária, Redes, América Latina.
\end{abstract}


Abstract: The approach to new possibilities for tourism development in various regions around the world is based on the understanding of how certain initiatives are constructed, such as communitybased tourism $(T B C)$. In this context, this article discusses some of these ongoing experiences in Latin America in light of the notion of networking. The method adopted to guide the proposed reflection is based on bibliographic and document research on the subject, complemented by the collection of survey data from the official websites of each initiative identified with this focus and linked to the Communitybased Tourism Network of Latin America (REDTURS). The data were processed by constructing a synthesis matrix, and interpreted using the technique of content analysis. Based on the main findings of the research, it was inferred that the TBC networks analyzed form a movement of cooperation, with actions focused mainly on travel and tourism marketing, exchanging and sharing of information, management and operationalization of businesses, influence on public policies, and strengthening local abilities and social mobilization, forming alliances at local, national and international levels. Keywords: Community-based tourism, Network, Latin America.

Resumen: El acercamiento a nuevas posibilidades para el desarrollo turístico en diversas regiones del mundo pasa por la comprensión de las iniciativas de construcción así designados como el turismo comunitario. En este contexto, el presente artículo pretende interpretar algunos de estos experimentos en curso en América Latina, a la luz de la noción de redes. La metodología adoptada para guiar la reflexión propuesta se basa en la investigación bibliográfica y documental sobre el tema, complementado por la información de las encuestas disponibles en las páginas de Internet de cada iniciativa identificada con este enfoque y vinculado a la Red de Turismo Comunitario de América Latina (REDTURS). La sistematización de los datos se basa en la preparación de una matriz de resumen y su interpretación se desarrolló mediante la adaptación de la técnica de Análisis de Contenido. Con base en los principales resultados de la investigación, fue posible reflexionar que las redes de TBC analizadas se configuran como un movimiento de articulación de acciones dirigidas, fundamentalmente, a la comercialización en el mercado de viajes y turismo, al intercambio y al compartimiento de información, a la gestión y operacionalización de emprendimientos, a la influencia en políticas públicas y al fortalecimiento de las capacidades locales y de movilización social, haciendo alianzas a nivel local, nacional e internacional. Palabras clave: Turismo comunitario, Redes, América Latina.

\section{Introdução}

No atual contexto de expansão internacional do turismo, a América Latina tem sido considerada como um "destino emergente", com um crescente fluxo de turistas (Meléndez, 2000) ou, ainda, como um "laboratório de alternativas" às determinações hegemônicas da crise contemporânea (Lang, 2016). Para uma melhor compreensão dessa afirmação, deve-se ter em vista que, desde 1970, o turismo na América Latina vem sendo interpretado como uma possível estratégia de desenvolvimento e de redução da pobreza. No entanto e, apesar de todas as potencialidades reconhecidas com essa direção, segundo Schlüter (1994), diversos impactos indesejáveis têm sido gerados pelo turismo nessa região, colocando em questão os seus reais êxitos em termos econômicos, sociais, culturais, ambientais e políticos.

Sendo assim, o desenvolvimento turístico latino-americano não pode ser interpretado de modo acrítico, tampouco como um processo naturalizado. Nesse sentido, na atualidade, essa região ${ }^{1}$ tende a representar um caso emblemático, para se refletir sobre a temática do desenvolvimento global e, por consequência, sobre o turismo e suas ambiguidades, nuances, riscos e incertezas de toda ordem.

Nessa perspectiva, é importante assinalar que, na maioria dos países latino-americanos, caminhos inovadores e dinâmicas alternativas em planejamento e desenvolvimento do turismo vêm sendo, progressivamente, construídos e

1 Importante ressaltar que não se pode considerar a América Latina apenas como um mero recorte geográfico em um mundo globalizado ou a partir de uma leitura estereotipada e equivocada de uma suposta homogeneidade cultural e linguística dos países que conformam essa região. Para se pensar a América Latina na contemporaneidade, deve-se apreender a sua significativa dimensão política e estratégica, em meio a disputas de interesses geopolíticos mundiais, em contraponto com interesses locais (Porto-Gonçalves e Quental, 2012). 
pactuados. Dentre essas propostas, iniciativas designadas como turismo de base comunitária, turismo comunitário ou turismo rural comunitário $(T B C)$ vêm ganhando cada vez mais visibilidade, como formas de resistências delineadas a partir de estratégias culturais e políticas enraizadas localmente, frente aos padrões convencionais do turismo massificado.

O fenômeno de TBC tem como premissa fundamental a base endógena em planejamento e desenvolvimentodo turismo. Essa nova perspectiva na América Latina tem sido interpretada como uma oportunidade para a melhoria de qualidade de vida por inúmeros grupos sociais ${ }^{2}$ em situação de vulnerabilidade social e ambiental e à margem de projetos turísticos convencionais na região (Bartholo, Sansolo e Bursztyn, 2009; Coriolano e Sampaio, 2013). Um aspecto também importante das iniciativas de $T B C$ se refere a sua vinculação às estratégias políticas desenvolvidas por grupos organizados e movimentos sociais para a garantia e para a preservação da cultura local e dos territórios por eles ocupados tradicionalmente. Ações nesse sentido vêm sendo lideradas pelos movimentos indígenas e do campo em vários países da América Latina $^{3}$ (Maldonado, 2009).

Esses processos têm contribuído para que o TBC venha sendo organizado por meio de ação coletiva e de redes locais, nacionais e latinoamericanas, permitindo apontar preocupações comuns e, também, construir alianças entre indivíduos, organizações e movimentos sociais que dividem esse pensamento, influenciando assim as agendas de políticas públicas e o delineamento de formas de comercialização nesse setor (Barbosa, 2011; Sampaio et al., 2014; Cañada, 2015). Dessa maneira, não se pode negligenciar a relevância de redes e articulações supralocais que vêm sendo engendradas, complexificando ainda mais a cena política e reconfigurando o debate dominante sobre desenvolvimento e modernidade (PortoGonçalves, 2006). Nesse caso, a construção de redes deve ser multiescalar, considerando que, segundo Vainer (2006, p.28), o poder de qualquer

2 Por exemplo, pescadores artesanais, etnias indígenas, agricultores familiares, ribeirinhos e camponeses. 3 Esses grupos sociais têm buscado resistir, frequentemente, aos projetos governamentais de desenvolvimento; às ações colonizadoras de "novas terras"; aos consórcios de extração de recursos florestais, minerais e petrolíferos; às empresas de exploração agrícola e pecuária; entre outras práticas altamente impactantes. estratégia transformadora diante dos processos contemporâneos de globalização está, mais do que nunca, "na capacidade de articular escalas, de analisar e intervir de modo transescalar", tal como parecem ilustrar os movimentos associados ao TBC.

Na América Latina, um exemplo desse tipo de organização do TBC tem se configurado por meio da Rede de Turismo Comunitário da América Latina (REDTURS), criada em 2001, com o objetivo de articular iniciativas que vêm sendo construídas em diferentes escalas locais e nacionais, influenciando o desenvolvimento de diferentes práticas na região. Entretanto, informações detalhadas e pesquisas sobre a gênese e o funcionamento dessas redes de turismo comunitário na América Latina são ainda limitadas ou quase inexistentes.

Neste contexto, algumas questões emergem como ponto de partida para a reflexão: Que tipo de rede se configura nas iniciativas de turismo de base comunitária? Quem são os atores sociais envolvidos e que ações esses mobilizam em rede? A partir dessa inquietação, o presente artigo tem o objetivo principal de interpretar algumas experiências de turismo de base comunitária em curso na América Latina à luz da noção de redes. Para tanto, o artigo está estruturado em quatro seções. A primeira busca discutir, teoricamente, sobre o turismo de base comunitária no contexto da América Latina. A segunda aborda a noção de rede na sociedade contemporânea. A terceira apresenta os procedimentos metodológicos da pesquisa. Em seguida, revelam-se os resultados e a análise das iniciativas latino-americanas de turismo comunitário autointituladas como redes e vinculadas à REDTURS, considerando os aspectos de organização, de formação de alianças e de intercâmbio intra e inter-redes.

\section{Turismo de base comunitária na América Latina: aporte teórico e contexto}

De maneira geral, pode-se afirmar que o campo teórico-conceitual do turismo de base comunitária (TBC) se encontra ainda em construção na América Latina, o que tende a envolver uma ampla e complexa perspectiva interpretativa sobre essa temática em nível regional.

As primeiras experiências de $T B C$ na região surgiram na década de 1980, por iniciativa de populações rurais e de origem 
indígena da região dos Andes e da América Central, associadas ao reconhecimento da importância de elementos socioculturais singulares e à grande beleza natural paisagística da região (Maldonado, 2009) ${ }^{4}$. Desde então, iniciativas de TBC vêm sendo identificadas em quase todos os países latinoamericanos, desde o México até o extremo sul na Argentina, considerando-se várias áreas de elevada biodiversidade e os seus laços históricos e culturais ${ }^{5}$. Os grupos sociais envolvidos, em conjunto com as alianças que são construídas com esse objetivo, vêm discutindo e promovendo ações em torno do TBC, desde 2001, por meio da Rede de Turismo Comunitário da América Latina (REDTURS), estimulada pela Organização Internacional do Trabalho (OIT).

Orientadas pelo marco da consagração dos direitos coletivos dos povos indígenas e tribais pela Convenção 169 da OIT (1989), as experiências de $T B C$ vêm se desenvolvendo inspiradas em princípios $^{6}$ derivados do reconhecimento e da valorização da visão de mundo (cosmovisão) própria desses povos sobre os valores e práticas sociais, culturais, religiosas e espirituais. Para esses grupos, natureza e cultura são indissociáveis. Sendo assim, esses grupos estariam ligados por um mesmo destino para garantir a harmonia do mundo que deve ser constantemente recriada, transcendendo o tempo e os indivíduos.

4 A origem dessas iniciativas se deve a diversos fatores de ordem econômica, social, cultural e política, os quais se relacionam, sobretudo, à pressão do mercado turístico internacional; à busca pela superação de uma situação de pobreza crônica; ao papel relevante das micro e pequenas empresas na sustentação do desenvolvimento local e, por fim, às estratégias políticas dos movimentos dos povos indígenas e das populações rurais para a preservação de seus territórios ancestrais (Maldonado, 2009).

5 Maldonado (2010), por exemplo, registrou mais de 300 destinos, incluindo cerca de 500 comunidades rurais e indígenas, com destaque para as experiências desenvolvidas no Equador, no Brasil, na Nicarágua e no Peru.

6 Esses princípios e valores estão expressos na Declaración de San José sobre Turismo Rural Comunitario (REDTURS, 2003), documento assinado por representantes comunitários da Bolívia, Brasil, Costa Rica, Equador, Guatemala e Peru, durante o II Encuentro Latino-Americano de Turismo Comunitário, realizado na Costa Rica, em 2003, pela REDTURS. Nesse documento, a concepção de TBC, baseada nos valores de solidariedade, cooperação, respeito pela vida e conservação e uso sustentável dos recursos naturais.
Por essa perspectiva, o $T B C$ se baseia $\square$ na propriedade e na autogestão sustentável dos recursos patrimoniais comunitários, de acordo com as práticas de cooperação e equidade no trabalho e na distribuição dos benefícios gerados pela prestação dos serviços turísticos $\square$ (Maldonado, 2009, p. 30). Para o autor, o diferencial da experiência de $T B C$ seria a sua dimensão humana e cultural, que busca incentivar o diálogo entre iguais e os encontros interculturais entre visitantes e visitados, na perspectiva de se conhecer e de se aprender com os modos de vida locais. Nesse caso, busca-se valorizar as manifestações culturais em articulação com a vivência dos atrativos naturais, históricos e recreativos.

No que tange propriamente ao processo de planejamento e de gestão dessas iniciativas, um diferencial importante das experiências turísticas de base comunitária tem sido, em geral, o alto nível de participação dos atores locais nas decisões coletivas e de articulação comunitária para se buscar soluções para os problemas comuns (Mendonça e Irving, 2004; Inostroza, 2008). Porém, mesmo reconhecendo o elevado grau de participação das populações locais no desenvolvimento do TBC na América Latina, Maldonado (2009) salienta que existem ainda várias deficiências e riscos que limitam a potencialidade das iniciativas em curso. Nesse caso, é preciso reconhecer limitações que podem existir nesse processo com relação à formação profissional e à capacidade de gestão de negócios, bem como ao acesso aos serviços públicos e infraestrutura básica, o que vem limitando a afirmação dessas iniciativas no mercado turístico global.

Embora a criação de "empresas em rede", na perspectiva horizontalizada de configuração (agrupamentos, parcerias ou clusters), venha sendo difundida, no âmbito da REDTURS, para apoiar a promoção comercial do TBC, parece haver ainda um consenso de que apenas as populações envolvidas e as alianças que são construídas com esse objetivo não podem enfrentar, por si mesmas, os desafios envolvidos na consolidação dessas iniciativas latino-americanas.

Por um lado, estudos de caso brasileiros, a título de ilustração, defendem que a gestão turística comunitária é o ponto central para o êxito de projetos de TBC. Esse processo resulta em sucesso, geralmente, quando iniciativas de TBC são institucionalizadas por meio de 
associações e cooperativas, desenvolvendo um trabalho de cadeia de valor como base para a produção associada ao turismo (Mielke e Pegas, 2013). Essa visão, no entanto, parece simplificar e reduzir a compreensão do processo complexo que envolve o TBC, considerando as comunidades locais apenas como componentes dos arranjos produtivos locais e, os visitantes, simplesmente, como consumidores de produtos e serviços.

Sob outra perspectiva, o desenvolvimento efetivo de experiências de TBC na América Latina implica também a necessidade de formulação de políticas públicas adequadas às reais demandas nesse campo. Todavia, os avanços para o estabelecimento de um marco legal para o TBC nos estados nacionais só foram possíveis devido à ação articulada por meio de redes, federações e associações locais, regionais e nacionais $^{7}$ (MALDONADO, 2009).

A importância da institucionalização e da promoção de redes de turismo comunitário, nas esferas nacionais e locais, foi expressa, marcadamente, na Declaración de Otavalo sobre Turismo Comunitario, sustentável, competitivo e com identidade cultural (REDTURS, 2001) $)^{8}$. Essa pode ser considerada como a primeira iniciativa de articulação em rede para a promoção dos destinos turísticos comunitários na América Latina.

Em sua origem, a REDTURS foi criada pela OIT em resposta às aspirações de diversas organizações de povos indígenas e comunidades tradicionais, cujo propósito foi intervir sobre a prática do $T B C$ e promover assistência técnica e respaldo institucional para facilitar o acesso de pequenos negócios rurais a serviços de desenvolvimento empresarial e a novos mercados. Com esse objetivo, a REDTURS foi fundada com a missão de apoiar os processos de formação e de fortalecimento de redes de turismo comunitário em países da América Latina, para diversificar as possibilidades de emprego e renda, promover o associativismo e a valorização da cultura local. Esta representa, assim, uma rede aberta, formada

7 Nesse sentido, Equador, Costa Rica, Guatemala, Nicarágua, Peru e Bolívia foram os países pioneiros na construção de instrumentos legais e de políticas específicas para o $T B C$.

8 Documento assinado por lideranças de comunidades tradicionais da Bolívia, Equador e Peru, durante o I Encuentro Técnico Internacional sobre Gestión del turismo sostenible y competitivo: Alianzas entre Estado, Empresa y Comunidad, realizado no Equador, em 2001, pela REDTURS. por povos indígenas, comunidades tradicionais e aliados que compartilham uma visão de $T B C$, por meio da qual se busca conciliar a eficiência econômica com a equidade social, a valorização das identidades culturais e a preservação dos recursos naturais (Maldonado, 2007).

Combasenessaperspectiva, foramorganizados, posteriormente à sua fundação, quatro encontros consultivos regionais da REDTURS ${ }^{9}$, nos quais ocorreram discussões sobre as oportunidades para o TBC. Nesses encontros, foram criadas regras para incrementar os processos associativos que procuram uma inserção competitiva da oferta de serviços nos mercados e fomentam o uso sustentável do patrimônio natural e cultural, priorizando também, por meio da qualificação dos recursos humanos e da formação de lideranças comunitárias, a busca pela melhoria da capacidade de autogestão (Maldonado, 2007).

Contudo, apesar de alguns avanços ocorridos no decorrer do processo, ainda existe uma série de dificuldades a ser enfrentada para o efetivo desenvolvimento de redes de TBC na América Latina. Essas são derivadas da restrita capacidade técnica de gestão dessas redes, da limitada qualidade da oferta de prestação de serviços com relação à demanda, da elevada dependência de recursos externos, do reduzido envolvimento dos membros da rede no processo, da condição de informalidade no estabelecimento de parcerias, da inexistência de políticas públicas específicas para esse tipo de iniciativa e da forte influência do setor turístico convencional, baseado na lógica do mercado (Maldonado, 2007).

Uma alternativa apontada para o enfrentamento desses problemas se refere às redes locais e nacionais serem as próprias gestoras das alianças e dos intercâmbios com esse objetivo. Ainda assim, permanece a incerteza da opção pela formalização ou não dessas redes para o seu funcionamento como meio de interlocução oficial do turismo comunitário nos seus países, sejam essas iniciativas entendidas como redes propriamente ditas ou como câmaras e federações com este objetivo (OIT, 2008).

Este parece ser um balizamento relevante para que se possa entender o alcance das propostas de TBC e as dificuldades enfrentadas para a consolidação de 9 Na Costa Rica, em 2003; no Panamá, em 2005; na Bolívia, em 2007; e na Guatemala, em 2008, com o apoio governamental e a participação de mais de 20 organizações de 13 países latino-americanos. 
suas redes na região. Sendo assim, a reflexão teórica sobre a noção de rede será abordada a seguir.

\section{A noção de rede para orientar a reflexão proposta}

O reconhecimento da importância das redes ganhou força e vem adquirindo novos significados, principalmente, a partir do século $\mathrm{XX}$, no contexto dos debates decorrentes da revolução da tecnologia, da informação e do conhecimento na sociedade contemporânea, o que parece ter contribuído expressivamente para a rápida difusão do termo em todo o mundo. Mas, apesar dessa tendência, esse termo é ainda polissêmico e controverso.

Para Castells (2010, p. 566), pensador contemporâneo de referência nesse debate, uma "rede é um conjunto de nós interconectados. Nó é o ponto no qual uma curva se entrecorta. Concretamente, o que um nó é depende do tipo de redes concretas de que falamos". Para o autor, os nós podem ser representados por indivíduos ou grupos de indivíduos de quaisquer organizações, seja do tipo formal ou informal, ou também lícita ou ilícita, abrangendo as múltiplas escalas entre o local e o global. Nessa perspectiva conceitual, o autor aponta que as redes no século XX passaram a constituir uma "nova estrutura social" ou uma "nova figura de poder", a partir da contribuição dos processos independentes de exigências de flexibilidade administrativa e globalização do capital, da produção e do comércio, ditadas pela dinâmica econômica, pelas demandas sociais e pelos avanços tecnológicos (Castells, 2010).

Com o avanço desse fenômeno no cenário mundial, a existência de redes vem definindo diversas formas de organização social e de conexões entre indivíduos, ainda que eles estejam dispersos espacialmente. Nesse contexto histórico, o fomento do uso da Internet $^{10}$ e a emergência das tecnologias de informação e comunicação (TICs) permitiram também disseminar a interação entre diversos atores nos meios midiáticos, o que tem sido importante para a construção de redes em diversas frentes (Castells, 2010).

Não obstante, do mesmo modo que os avanços tecnológicos permitiram o fluxo global de capitais,

10 A internet passou a ser a principal ferramenta para o fluxo e para a troca de informação, de comunicação e de capital em escala mundial. estes contribuíram também para articular, em forma de redes, uma ampla variedade de ações coletivas, de movimentos sociais e populares e de organizações da sociedade civil em torno de questões vinculadas à educação, à cultura, à assistência social, ao combate à fome, à proteção da biodiversidade, ao trabalho, entre tantos outros campos da vida social. Por isso, a noção de redes pode traduzir uma "ideia-força" que se caracteriza, sobretudo, pelo "seu poder criador de ordens novas e seu caráter libertador", o que tende a enfatizar uma condição democrática, aberta e emancipatória (Costa et al., 2003, p.9).

Nesse campo de debate, as redes se tornaram a principal forma de expressão e organização coletiva, no plano político e na ampla articulação social, de alcance nacional ou internacional, de antigos sujeitos sociais, em processo de transformação, e de novos sujeitos emergentes nesse contexto para limitar e/ou influenciar as ações do Estado e do mercado ${ }^{11}$ (Gohn, 2010).

A organicidade de redes sociais se fundamenta também em relações de poder e na cultura de cada região, considerando associações informais de intercâmbio em sistemas formais. Nesse tipo de rede, o intercâmbio se caracteriza por relações horizontais (quando a troca ocorre entre as partes reciprocamente) e verticais (quando a troca ocorre de forma assimétrica), caso em que o processo de organização de redes pode, inclusive, estabelecer níveis de hierarquia de poder. Além disso, como sistemas de intercâmbio, essas redes são, geralmente, facilitadas pelo grau de parentesco e amizade entre os indivíduos e traduzidas em diferentes graus de proximidade (Lomnitz, 2009). Também se considera, nesse processo organizativo de redes, a implicação dos laços de solidariedade, de lealdade e de confiança, o qual representaria um possível mecanismo "amortecedor" para o enfrentamento dos problemas sociais contemporâneos. Com esse propósito, "redes sociais de reciprocidade baseadas na ajuda mútua e na confiança constituem, na era global, estratégias fundamentais de sobrevivência para uma grande parte da população mundial" (Lomnitz, 2009, p. 31).

Por essa via de interpretação, as redes de intercâmbio de solidariedade envolvem relações

11 Nesse quadro, está inserida uma ampla variedade de ONGs, fundações de origens distintas, entidades do terceiro setor, movimentos sociais globais, inter ou transnacionais, e cooperativas de produção solidária. 
econômicas informais, que se referem às atividades produtivas e distributivas de bens e serviços, às empresas e aos indivíduos que não são regulamentadas pelas instituições legais. Desse modo, afirma Lomnitz (2009, p. 59), são as redes essenciais para a operação da economia informal, visto que representam uma "base de poder" para a aquisição de recursos escassos e um tipo de "seguro coletivo" contra ameaças do sistema formal. Mas, ao mesmo tempo, essas estruturas são, de alguma forma, articuladas às relações sociais e de produção da economia formal. Nessa dinâmica de redes, ocorrem conflitos de interesses entre os direitos e os deveres formais e informais e as ideologias rivais, que impulsionam a definição de controles e regras próprias de intercâmbio e convivência.

A constituição morfológica e a dinâmica de operação de uma rede são também discutidas por Pedro (2003). Para a autora, a força dos agenciamentos internos, a qual permite melhor definir uma rede. Uma pista do que torna uma rede forte "é que cada um de seus pontos se apóia em outros", o que leva a entender que "a força deixa de ser um atributo individual para se tornar uma questão de relações e de alianças" (Pedro, 2003, p. 34), implicando o entendimento do seu caráter dinâmico de construção coletiva. A existência de uma rede se deve a um conjunto de negociações bem-sucedidas, o que provoca a necessidade de se traçar a sua gênese, entendendo que a historicidade de cada processo se fabrica a partir de características próprias e diferenciadas. Ademais, na dinâmica das redes, é preciso compreender como o surgimento de controvérsias e de impasses é resolvido ou contornado (Pedro, 2008).

O avanço do debate com esse direcionamento tem sido inspirado, de forma diferenciada, pela abordagem da Teoria Ator-Rede (TAR), defendida por Latour (2012). Segundo a TAR, o entendimento sobre redes pode ser expresso pela ideia de que existem vários fios que conectam o social sem, necessariamente, formar uma unidade, mas, sim, configurando um processo contínuo de associações. Nesse caso, a rede de atores sociais é aberta e heterogênea, de modo que seja possível o estabelecimento de todo e qualquer tipo de conexão. Dessa forma, o trabalho, o movimento, o fluxo e as mudanças resultantes de associações produzidas, conjuntamente, por humanos e não humanos, são enfatizados no processo investigativo inspirado pela TAR. Assim, um dos desafios da pesquisa sobre redes deve ser seguir e transpor os "rastros" deixados pelos atores, considerando, nesse percurso, as conexões e as implicações de tais alianças (Latour, 2012).

Com base nas premissas teóricas discutidas sobre a noção de rede, este artigo busca contribuir para a sua compreensão como uma "nova estrutura social e de poder", que é também resultado da expressão e da organização de movimentos sociais, ações coletivas e organizações da sociedade civil. Assim, é possível considerar que o seu entendimento implica a análise de relações e de alianças formais e informais, baseadas, muitas vezes, em princípios de solidariedade e confiança. Essas envolvem elementos humanos, materiais, técnicos e simbólicos, para a promoção de intercâmbio e compartilhamento de informação, conhecimento, capitais e recursos no processo de organização coletiva de grupos sociais em diversos contextos, muitos deles de vulnerabilidade social, como ocorrem em muitas iniciativas de turismo de base comunitária na América Latina.

\section{Caminhos metodológicos da pesquisa}

A investigação proposta neste artigo apresenta caráter exploratório e interdisciplinar, inspirado em Vasconcelos (2002), pois busca compreender fenômenos e processos complexos, ainda pouco conhecidos ou sistematizados, de maneira ampla e aberta. Além disso, a prática "inter" é fundamental no caminho do pensamento complexo, por permitir a interação entre diversos campos do saber, de forma horizontal, visando à recombinação dos elementos constituintes. Sendo o turismo um campo interdisciplinar, uma possibilidade se abre para pensar e discutir a sua problemática, uma vez que a abordagem desse complexo fenômeno depende do estudo minucioso de inúmeras e incomensuráveis áreas do agir humano (Panosso Netto, 2011).

Com base nessa orientação metodológica, a primeira etapa compreendeu a pesquisa bibliográfica para subsidiar a construção teórica dos temas centrais de reflexão sobre turismo de base comunitária no contexto na América Latina. Além disso, para orientar a reflexão proposta, a discussão teórica se fundamentou na noção polissêmica de redes. O levantamento bibliográfico foi realizado por meio de consulta ao Portal de Periódicos da Coordenação de Aperfeiçoamento de Pessoal de Nível Superior (Capes), vinculado ao Ministério da Educação/Brasil; ao Google Acadêmico; e à Rede de Revistas Científicas da América Latina 
e do Caribe, Espanha e Portugal (Redalyc). Posteriormente, a pesquisa documental foi desenvolvida por meio de consulta à documentação técnica relacionada aos encontros consultivos regionais da REDTURS, realizados no período de 2001 a 2008, tendo sido consultados os sites oficiais relativos aos casos escolhidos para análise.

A segunda etapa metodológica consistiu na sistematização e na análise de todo o material obtido. As informações foram sistematizadas em uma matriz síntese, buscando-se articular os perfis de 16 redes latino-americanas de turismo comunitário, mapeadas conforme o vínculo estabelecido com a REDTURS e por se autointitularem como redes. A análise dos resultados foi realizada por meio da adaptação da técnica Análise de Conteúdo (Bardin, 1994), que se constitui como um conjunto de técnicas utilizadas no sentido de contribuir para o processo de busca e de reconhecimento do conteúdo das mensagens investigadas. O procedimento da análise de dados foi iniciado com a leitura minuciosa dos documentos e de páginas na internet, sendo um website ou perfil de rede social, e a categorização temática, a partir do referencial teórico orientador. Essas categorias envolveram: a) o modo de organização das redes; b) o estabelecimento (ou não) de alianças estratégicas e parcerias; c) a promoção de intercâmbios de experiências e o compartilhamento de elementos materiais e imateriais. Para o aprofundamento da abordagem sobre o objeto de pesquisa, em seguida, realizou-se a interpretação dos dados, articulando as questões investigativas, os resultados obtidos, as inferências realizadas e a perspectiva teórica orientadora, a ser apresentada adiante.

\section{Resultados e discussóes sobre $T B C$ na América Latina pela perspectiva de redes}

A partir do portal virtual da REDTURS (www. redturs.org), segundo a metodologia proposta, foram identificadas 16 experiências de $T B C$ autodenominadas como redes na América Latina, conforme sistematizado no Quadro 01.

As informações sistematizadas no Quadro 01 revelam a cronologia do processo de criação, na América Latina, de redes de turismo comunitário vinculadas à REDTURS, em sua maioria, originadas entre os anos 2001 e 2008. Essa tendência parece ter sido impulsionada pelas ações da REDTURS, especialmente, no que se refere aos encontros regionais. Considerando que a maioria das redes mencionadas tem menos de 10 anos de existência, é possível afirmar também que o desenvolvimento de redes de TBC na América Latina representa um fenômeno recente, mas que envolve a maioria dos países da região, dentre os quais se destacam o Equador e a Argentina, com maior número de redes articuladas em escalas local e nacional. Quanto à abrangência territorial das redes identificadas, as iniciativas em curso estão, em geral, localizadas em áreas rurais e no entorno de unidades de conservação, o que potencializa o contato e a valorização da natureza preservada e da cultura indígena e de comunidades tradicionais.

Mas, uma vez descritas e sistematizadas, seriam as iniciativas identificadas de fato consideradas como redes, segundo o referencial teórico adotado neste artigo? Para aprofundar a reflexão sobre essa questão e de acordo com a literatura pesquisada, foram estabelecidas três categorias temáticas: a) o modo de organização de redes (tipos de entidades formais e informais); b) o estabelecimento de alianças estratégicas (interesses e alcance em escala) e c) os meios de intercâmbio e compartilhamento (incluindo, nesse caso, elementos materiais e imateriais das iniciativas envolvidas).

Com relação ao modo de organização, podese afirmar que as redes pesquisadas se configuram, sobretudo, na forma de associações e cooperativas sociais, conforme os casos mencionados anteriormente na Costa Rica, México, Argentina e Bolívia, tendo como pressuposto comum a autogestão e a participação dos grupos sociais envolvidos. Dessa maneira, parece existir uma dinâmica de construção coletiva com relação às iniciativas de turismo comunitário, sendo muitas delas organizadas como $\square$ empresas em rede $\square$ (Maldonado, 2009), segundo uma perspectiva horizontal de gestão, para formalizar a sua inserção no mercado de viagens nacional e internacional, conforme pode ser ilustrado pela experiência da RITA (México). Em alguns casos, como do Equador e do México, a questão de comercialização de pacotes e prestação de serviços tem sido também priorizada no processo, o que tende a incentivar a criação de agências e de operadoras de viagens e turismo com esse objetivo.

Mas o que parece caracterizar mesmo essas redes como experiências de turismo comunitário 
Quadro 01: Matriz-síntese dos casos autorreferidos como redes de TBC na América Latina.

\begin{tabular}{|c|c|}
\hline NOME & OBIETIVO E DESCRICÃO \\
\hline $\begin{array}{l}\text { Red Indigena de } \\
\text { Comunidades del } \\
\text { Alto Napo para } \\
\text { la Convivencia } \\
\text { Intercultural } \\
\text { y Ecoturismo } \\
\text { (RICANCIE) } \\
\text { Equador - } 1993\end{array}$ & $\begin{array}{l}\text { Objetivo: Desenvolver ações para a proteção dos recursos naturais e culturais, } \\
\text { a melhoria da qualidade de vida das famílias Quichuas, o fortalecimento da } \\
\text { autoestima dos moradores locais e a promoção de uma alternativa à agricultura } \\
\text { intensiva, oferecendo serviços turísticos comunitários de qualidade, com } \\
\text { guias nativos capacitados. Dessa forma, busca-se também eliminar formas de } \\
\text { "turismo agressivo", que ameaçam o equilíbrio sociocultural e ambiental e } \\
\text { evitar a migração dos jovens para as cidades. } \\
\text { Descrição: Em sua origem, construiu-se uma infraestrutura necessária para } \\
\text { operar, antes de se constituir oficialmente como RICANCIE, baseada na } \\
\text { participação comunitária. Em 2007, a RICANCIE se converteu na Corporación } \\
\text { Provincial de Turismo Comunitario de Napo, sendo líder e pioneiro na prestação } \\
\text { de serviços turísticos comunitários na Amazônia Equatorial. Envolve oito } \\
\text { Comunidades Quichua (Rio Blanco, Runa Wasi, Chuva Urku, Wasila Talag, } \\
\text { Machakuvaku. Sinchipura. Alukus e Limoncocha). }\end{array}$ \\
\hline $\begin{array}{l}\text { Consórcio } \\
\text { Cooperativo Red } \\
\text { Ecoturística Nacional } \\
\text { (COOPRENA R. } \\
\text { L) } \\
\text { Costa Rica - } 1994\end{array}$ & $\begin{array}{l}\text { Objetivo: Fomentar o desenvolvimento sustentável, a partir da base associativa } \\
\text { e das comunidades rurais, por meio de estratégias inovadoras que utilizam } \\
\text { o turismo como alternativa para o desenvolvimento local com qualidade, } \\
\text { eficiência, transparência e com responsabilidade social, ambiental e cultural. } \\
\text { Descrição: Suas ações estratégicas são voltadas para o apoio técnico, o } \\
\text { fortalecimento de capacidades locais, do mercado e da comercialização } \\
\text { do turismo por meio da sua própria agência de viagens Simbiosis Tours, a } \\
\text { gestão de fundos de investimentos, a influência em política pública, e a } \\
\text { articulação com parceiros que atuam nas áreas de economia social, ambiental } \\
\text { e desenvolvimento sustentável. Apoia-se em alianças locais e internacionais. } \\
\text { Envolve } 23 \text { organizações de economia social, com inserção em todo o país, } \\
\text { sendo a maioria como cooperativas e a minoria associacões. }\end{array}$ \\
\hline $\begin{array}{l}\text { Red Provincial } \\
\text { de Imbabura } \\
\text { (RUNATUPARI) } \\
\text { Equador - } 2001\end{array}$ & $\begin{array}{l}\text { Objetivo: Conectar visitantes e moradores, facilitar uma aprendizagem mútua, } \\
\text { e implementar o "turismo sustentável", evitando a degradação da natureza e } \\
\text { valorizando a cultura indígena e local. } \\
\text { Descrição: Uma operadora de turismo comunitário que desenvolve o TBC } \\
\text { na região, com o pressuposto da participação ativa das comunidades rurais, } \\
\text { buscando criar novas fontes de renda e trabalho e agregar valor à cultura, } \\
\text { às tradições e ao patrimônio local. Fundada pela União de Organizações } \\
\text { Campesinas e Indígenas de Cotacachi e quatro comunidades indígenas de } \\
\text { Cantón Cotacachi. }\end{array}$ \\
\hline $\begin{array}{l}\text { Red de Turismo } \\
\text { Comunitario } \\
\text { Garífuna (MUTU) } \\
\text { Honduras - 2001 }\end{array}$ & $\begin{array}{l}\text { Objetivo: Lutar em defesa do território ancestral da comunidade Garífuna } \\
\text { e resistência à pressão internacional dos projetos de complexos hoteleiros e à } \\
\text { especulação imobiliária. } \\
\text { Descrição: Organização que, voltada à autonomia de povos indígenas, desenvolve } \\
\text { projetos, cujos atores têm alguma forma de protagonismo, a partir da compreensão } \\
\text { do turismo comunitário como uma alternativa para a geração de emprego digno } \\
\text { e bem remunerado para atenuar a pobreza da população local discriminada, } \\
\text { buscando, ainda, a preservação da segurança alimentar e com o cuidado de evitar a } \\
\text { dependência com relação ao turismo. A maior parte dos projetos de turismo vem } \\
\text { sendo gestionada e representada pelas mulheres Garífunas. }\end{array}$ \\
\hline $\begin{array}{l}\text { Red de Parques } \\
\text { Indigenas del Mapu } \\
\text { Lahual } \\
\text { Chile - } 2001\end{array}$ & $\begin{array}{l}\text { Objetivo: Preservar as florestas da Cordilheira da Costa para as futuras } \\
\text { geraçóes, resgatar e valorizar os conhecimentos tradicionais e gerar alternativas } \\
\text { de emprego e renda para as famílias das comunidades locais, por meio do } \\
\text { ecoturismo, do artesanato e de outras atividades compatíveis com a conservação } \\
\text { da natureza. } \\
\text { Descrição: Conjunto de comunidades locais, que utilizam o ecoturismo como } \\
\text { estratégia de desenvolvimento político-territorial e fomento produtivo, em } \\
\text { uma região de elevada biodiversidade e sob forte pressão econômica externa. } \\
\text { Envolve as Comunidad Caleta Condora, Comunidad Loy Cumilef, e Comunidad } \\
\text { Maicolpue Rio Sur. }\end{array}$ \\
\hline
\end{tabular}


Red Indígena de Turismo de México (RITA)

México - 2002

Rede Brasileira de

Turismo Solidário

Comunitário

(TURISOL)

Brasil - 2003
Objetivo: Promover e fortalecer a sustentabilidade dos serviços turísticos indígenas, para a conservação do patrimônio cultural e ambiental, que formam uma das bases para o desenvolvimento do "bien vivir", mediante o acesso à informação; o fortalecimento de capacidades e tecnologias apropriadas; e o fomento à participação ativa e corresponsabilidade de seus associados no processo. Descrição: Associação civil de empresas, que busca fazer com que os seus associados avancem no exercício dos direitos fundamentais, especificamente, dos povos indígenas, reconhecidos pelo Estado Mexicano, integrando participativamente estratégias de fortalecimento humano, social, econômico e produtivo. Envolve 120 empresas associadas, com 12 redes estatais de turismo. Objetivo: Fortalecer o turismo de base comunitária no país, com enfoque na formação e na capacitação dos integrantes da rede, por meio de eventos e encontros de formação; produção de conhecimento a partir de materiais didáticos, publicações e vídeos; diálogo com interlocuções das políticas públicas; criação e promoção de estratégias de comercialização dos projetos de TBC.

Descrição: Rede informal formada pela união de diversas organizações com atuação em projetos de turismo solidário que buscam trocar experiências, fortalecer as iniciativas existentes e despertar outras comunidades para a construção de um turismo diferente. Envolve 12 projetos, que beneficiam 100 comunidades, de 61 municípios em oito estados brasileiros.

Red de Turismo

Rural de Base

Comunitaria

(HUELLA

GAUCHA)

Argentina - 2004

Red Nicaragüense

de Turismo Rural

Comunitário

(RENITURAL)

Nicarágua - 2005

Objetivo: Consolidar os empreendimentos que já operam o TBC, mediante ações de capacitação, assessoria, gestão de fundos e promoção de marketing, buscando fortalecer-se por meio da incorporação de outros empreendedores da província.

Descrição: Constitui-se como uma Associação de Produtores La Huella Gaucha, que conta com o apoio da Secretaria de Turismo provincial, e desenvolve a prática do turismo comunitário. Abrange os destinos Barro Blanco, Cañadas San Basilio, Ecoturs y Hostal Ocloyas (Província de Jujuy), e oito iniciativas familiares locais.

Objetivo: Promover a gestão e o fortalecimento de iniciativas turísticas comunitárias, que estão operando nas áreas rurais de Nicarágua, buscando a melhoria da qualidade dos serviços e dos produtos turísticos ofertados, a difusão e a promoção da comercialização da oferta turística da rede e a promoção do desenvolvimento de políticas turísticas nacionais que beneficiem os seus membros.

Descrição: O turismo de base comunitária se desenvolve no sentido da gestão e da propriedade privada e comunitária, valorizando os povos, a natureza, a cultura, as tradições, o patrimônio arqueológico e promovendo espaços de intercâmbio social e cultural com os visitantes, de forma que se consolide o direito à terra pelos campesinos. Fundada pela União de Cooperativas Agrícolas (UCA) Miraflor, Estelí, com a participação de 22 organizações, que agrupam cerca de 35 iniciativas turísticas comunitárias.

Red Argentina de

Turismo Rural

Comunitário

(RATURC)

Argentina - 2006

Objetivo: Contribuir para o desenvolvimento local, mediante o fortalecimento da autogestão comunitária do turismo, sustentado nos princípios de reciprocidade, participação e valorização do patrimônio natural e cultural, garantindo o respeito aos territórios ancestrais e a identidade dos povos originários e das comunidades campesinas.

Descrição: Organização de alcance nacional, que possui uma central de comunicação administrada pelo Ministério do Turismo da Argentina. Por isso, a rede busca avançar em seu processo de autogestão, para facilitar a comunicação entre operadores, viajantes e comunidades locais. Abrange 40 comunidades nas regiões norte, do litoral, da Patagônia e de Cuyo.

Red de Turismo de Chiapas

Ecotours y Etnias

(SENDASUR)

México - 2006
Objetivo: Promover um turismo alternativo e respeitoso com a natureza e os homens e mulheres que a habitam; proporcionar a seus membros e usuários serviços de promoção, difusão, comercialização e compartilhar com o viajante os valores, a diversidade, a riqueza e a beleza das paisagens locais e de seu povo. Descrição: Agência de viagens que opera em San Cristobal de las Casas, Chiapas, ofertando pacotes de viagem aos 16 centros ecoturísticos. Envolve 16 Centros Ecoturísticos Comunitários do Estado de Chiapas, a região Selva Lacandona e Selva el Ocote. 


\begin{tabular}{|c|c|}
\hline $\begin{array}{l}\text { Red Boliviana de } \\
\text { Turismo Solidario y } \\
\text { Comunitario } \\
\text { (TUSOCO) } \\
\text { Bolívia - 2006 }\end{array}$ & $\begin{array}{l}\text { Objetivo: Apoiar o desenvolvimento de iniciativas e empreendimentos de } \\
\text { turismo solidário comunitário que se configuram nas comunidades rurais } \\
\text { da Bolívia, em particular as campesinas e indígenas. Por meio do turismo, as } \\
\text { comunidades buscam complementar a sua economia para melhorar a qualidade } \\
\text { de vida de seus habitantes. Também tem o objetivo de resgatar e valorizar o } \\
\text { patrimônio natural e cultural. } \\
\text { Descrição: As atividades desenvolvidas se dirigem ao fortalecimento do } \\
\text { trabalho dos empreendimentos associados, tanto no aspecto organizacional } \\
\text { quanto na melhoria dos seus serviços; à promoção dos produtos turísticos; à } \\
\text { comercialização dos roteiros por meio da agência Tusoco Viajes; à gestão ambiental } \\
\text { do turismo à articulação com as instâncias públicas parceiras. Envolve mais de } \\
70 \text { iniciativas diretamente geridas pelas comunidades e povos bolivianos. }\end{array}$ \\
\hline $\begin{array}{l}\text { Red de Turismo } \\
\text { Comunitario } \\
\text { Huataraco Suno } \\
\text { (RETHUS) } \\
\text { Equador-2008 }\end{array}$ & $\begin{array}{l}\text { Objetivo: Promover o desenvolvimento de suas comunidades, por meio do } \\
\text { turismo comunitário, segundo os princípios de sustentabilidade, igualdade, } \\
\text { respeito pela natureza e preservação da cultura local. } \\
\text { Descrição: Operadora de promoção de programas orientados a facilitar } \\
\text { a observação e o contato com a natureza, e a conhecer e valorizar a cultura } \\
\text { tradicional. Abrange } 20 \text { comunidades indígenas kichwas del Cantón Loreto. }\end{array}$ \\
\hline $\begin{array}{l}\text { Red de Turismo } \\
\text { Campesino Valles } \\
\text { Calchaquíes de Salta } \\
\text { Argentina - } 2008\end{array}$ & $\begin{array}{l}\text { Objetivo: Promover a autogestão da operação do turismo responsável e da } \\
\text { venda dos artesanatos, com base nos princípios da economia social, do respeito à } \\
\text { diversidade e à equidade social, do trabalho associativo, a partir da identidade local. } \\
\text { Descrição: Cooperativa que oferece serviços de turismo rural comunitário e } \\
\text { uma diversidade de produtos artesanais. A cooperativa funciona em sistema de } \\
\text { rotação dos serviços turísticos, para garantir que todas as famílias cooperadas } \\
\text { participem da repartição dos benefícios gerados pelas atividades. Parte do } \\
\text { valor arrecadado pela venda dos serviços é destinada a um fundo comum } \\
\text { solidário. Nesta Rede, estão engajadas } 50 \text { famílias de pequenos agricultores e } \\
\text { artesãos, residentes em } 12 \text { comunidades da região do Valles Calchaquíes no sul } \\
\text { da Província de Salta. }\end{array}$ \\
\hline $\begin{array}{l}\text { Rede Cearense de } \\
\text { Turismo Comunitário } \\
\text { (TUCUM) } \\
\text { Brasil - } 2008\end{array}$ & $\begin{array}{l}\text { Objetivo: Fortalecer e dar visibilidade às iniciativas de TBC no estado do } \\
\text { Ceará. Entre os seus princípios comuns estão a solidariedade, a distribuição } \\
\text { equitativa de renda, a valorização da produção, da cultura e da identidade local } \\
\text { e da sustentabilidade socioambiental. } \\
\text { Descrição: Rede informal, cuja agenda inclui açães para o fortalecimento dos } \\
\text { grupos fragilizados; a busca pelo acesso às políticas públicas; a promoção de } \\
\text { cursos de formação em gerenciamento de emprendimentos socioprodutivos; } \\
\text { a valorização dos eventos culturais locais; a ação de mobilização ambiental e } \\
\text { o intercâmbio de experiência com outras redes. Abrange } 11 \text { comunidades, } 03 \\
\text { pontos de hospedagem solidária e 03 ONGs de apoio institucional: Instituto } \\
\text { Terramar (Brasil), Associação Caiçara (Brasil) e Associação Tremembé (Itália). }\end{array}$ \\
\hline $\begin{array}{l}\text { Red de Turismo } \\
\text { Comunitario del Lago } \\
\text { Titicaca (APTHAPI) } \\
\text { Bolívia - } 2009\end{array}$ & $\begin{array}{l}\text { Objetivo: Reunir as comunidades para compartilhar aprendizagens e } \\
\text { conhecimentos, capacidades operativas voltadas ao mercado turístico, mas, } \\
\text { principalmente, os benefícios econômicos gerados pelo desenvolvimento das } \\
\text { atividades turísticas para a redistribuição entre as comunidades envolvidas. } \\
\text { Descrição: Rede de associaçóes de empreendimentos turísticos comunitários, } \\
\text { que oferta serviços de turismo para visitantes na região do Lago Titicaca. } \\
\text { Constitui uma instância criada para consolidar um modelo de gestão associativo, } \\
\text { exercido por parte de comunidades membros, no âmbito sócio organizativo } \\
\text { e empresarial. Abrange } 50 \text { empreendimentos turísticos familiares de origem } \\
\text { Aymara, vinculados às Associações de Turismo Comunitário de Challapampa } \\
\text { - Isla del Sol, Coati - Isla de la Luna, Sampaya e Santa Ana - Península de } \\
\text { Copacabana, e Sahuiña em Copacabana. }\end{array}$ \\
\hline
\end{tabular}

Fonte: Elaboração das autoras. 
é o compromisso pactuado em suas propostas com relação às consequências que esses serviços podem gerar para a conservação e valorização da natureza, da cultura e da tradição no lugar visitado e em termos de renda e trabalho para a população local dos destinos comercializados.

Em outros casos (como os projetos de Honduras, Chile, Brasil e Nicarágua), as redes de TBC parecem se configurar a partir de vínculos informais entre os envolvidos, por meio de movimentos sociais, ONGs e ações coletivas com força política, cujos interesses em defesa do território tradicional são considerados prioritários. Nesse caso, essas redes tendem a ter importante papel para a operação da economia informal e a aquisição de recursos escassos e também como um "seguro coletivo" contra ameaças do mercado dominante formal, conforme discute Lomnitz (2009). Algumas redes na América Latina, entretanto, parecem ter sido impulsionadas por iniciativas governamentais e se constituem como um tipo de "central" de comunicação de informações turísticas de base comunitária, como ilustra o caso da RATURC (Argentina), que busca promover a ponte entre operadoras, viajantes $\mathrm{e}$ populações receptoras. Assim, são inúmeras as configurações possíveis e os objetivos envolvidos nesse processo.

Importante enfatizar também, na análise proposta, a diversidade de atores sociais que integram essas redes, envolvendo, em sua maioria, representantes de etnias indígenas, camponeses, agricultores familiares, pescadores artesanais e populações extrativistas que vivem em lugares de elevada riqueza ecossistêmica, mas em situação de vulnerabilidade socioeconômica. Esses atores sociais compõem uma mescla de empreendimentos comunitários e/ou familiares, associações, cooperativas sociais, agências e/ou operadoras de viagens e ONGs com vários perfis no processo de configuração dessas redes.

Não obstante, parece haver uma diferença importante entre as redes locais e nacionais. De maneira geral, as redes nacionais tendem a congregar associações, cooperativas sociais, ONGs e comunidades locais, de acordo com a sua realidade de inserção, o que tende a ampliar o seu alcance com relação ao número de membros e à articulação de apoio, parcerias e alianças, como ocorre com os casos da RENITURAL (Nicarágua), da TUSOCO (Bolívia), da COOPRENA (Costa Rica) e da TURISOL (Brasil). No caso de algumas redes locais, por outro lado, estas são constituídas, geralmente, por famílias ou grupos familiares organizados, como ilustram os empreendimentos turísticos ligados à MUTU (Honduras), SALTA (Argentina), CHIAPAS (México), TUCUM (Brasil) e MAPU LAHUAL (Chile). Nesses casos, os nós dessas redes tendem a se constituir em interações sociais facilitadas pelo grau de parentesco, conforme discute Lomnitz (2009).

Com relação ao modo de estabelecimento de alianças, a maioria das redes de $T B C$ pesquisadas se apoia em alianças locais, nacionais e internacionais, envolvendo lideranças comunitárias, instituições públicas, operadores privados de turismo e ONGs de perfis diversos. Um aspecto comum nesse processo é a articulação dessas iniciativas com as organizações de base do movimento indígena e de comunidades tradicionais. Outra forma por meio da qual são estabelecidas as alianças se expressa pelo fomento à participação ativa e à corresponsabilidade dos associados nas ações de interesse comum, o que tende a gerar um sentimento de pertencimento e a fortalecer os laços entre os membros. Também ocorrem casos de redes, como a RATURC (Argentina), as quais contam com o apoio de órgãos governamentais, o que parece favorecer o diálogo intersetorial para desdobramentos efetivos em políticas públicas. Além disso, alguns casos (como a TUCUM, Brasil) se apoiam em ONGs que, muitas vezes, recebem assessoria técnica para o processo de organização da rede e de articulação dos grupos comunitários envolvidos. Ressalta-se ainda que a própria aliança dessas redes com a REDTURS tende a facilitar o seu acesso às agências de cooperação internacional no âmbito das Nações Unidas, como a Organização Internacional do Trabalho e a Organização Mundial do Turismo, conforme salientado por Maldonado (2007). Assim, o estabelecimento de alianças parece se constituir como uma estratégia vantajosa para o desenvolvimento do TBC em rede na América Latina.

Quanto às relações de intercâmbio e compartilhamento, os resultados da pesquisa documental indicam que essas envolvem o intercâmbio de recursos, de serviços, de informações, de conhecimento e de oportunidades para a formação e aprendizagem, como ilustram as iniciativas da TURISOL e TUCUM (Brasil), SENDASUR (México) e APTHAPI (Bolívia). Esse intercâmbio tende a 
facilitar uma aprendizagem baseada no princípio de ajuda mútua, com enfoque na formação e na capacitação dos integrantes das redes por meio de encontros de formação e outros eventos com objetivos semelhantes.

Nessas oportunidades, busca-se promover o intercâmbio de experiências, o fortalecimento das iniciativas existentes e o incentivo a outras comunidades para a construção de propostas conjuntas de TBC. Da mesma forma, esse intercâmbio entre alguns indivíduos e grupos parece ser também facilitado pelo grau de parentesco (caso análogo aos empreendimentos familiares da APTHAPI) e pelo uso das tecnologias de informação e de meios de comunicação (sites e telefones $)^{12}$, como ocorre com todas as iniciativas pesquisadas. Complementarmente, materiais didáticos, publicações e vídeos são elaborados, visando ao compartilhamento com outras redes e mídias sociais.

Além disso, o intercâmbio com outras redes para o compartilhamento de conhecimentos e boas práticas ocorre por meio de encontros, grupos de trabalho e oficinas para fortalecer o movimento do $T B C$, baseado em relações de solidariedade, conforme mencionado nos documentos da REDTURS supracitados. Outro tipo de intercâmbio nas experiências analisadas parece ocorrer na relação entre os visitantes e os visitados, a partir do pressuposto de contato com o patrimônio, o modo de vida local e a história de resistência e luta pela garantia e pela preservação de territórios ocupados tradicionalmente. Por todas essas razões, as relações de intercâmbio e compartilhamento parecem representar uma condição essencial para o movimento em rede no $T B C$ na América Latina.

Assim, pela análise realizada, a construção coletiva de redes de TBC na América Latina vem sendo desenvolvida como uma estratégia de resistência ao turismo convencional, esse entendido como um $\square$ turismo agressivo e excludente $\square$ (que gera potencialmente ameaças ao equilíbrio sociocultural e ambiental dos lugares), e à pressão internacional pela imposição recorrente de projetos de complexos hoteleiros com consequências no processo de especulação imobiliária deles derivada. Além disso, essas redes se traduzem como alternativas para minimizar

12 Nessas ocorrências, os sites de redes de TBC podem favorecer, até mesmo, as iniciativas comunitárias que possuem uma página individual gerida de forma autônoma (Cabanilla e Gentili, 2015). as práticas de agricultura intensiva e para conter a migração de jovens do campo para as cidades. Da mesma forma, como é possível perceber na descrição previamente sistematizada, as redes pesquisadas são configuradas também para influenciar políticas públicas no sentido de fortalecimento do turismo comunitário, a exemplo da TUSOCO (Bolívia), COOPRENA (Costa Rica), TURISOL e TUCUM (Brasil), RENITURAL (Nicarágua).

Pela presente pesquisa, é importante enfatizar também que os nós das iniciativas em redes de $T B C$ em curso na América Latina parecem estar em constante construção, sendo articulados e reforçados pelos atores sociais envolvidos em uma dinâmica no tempo e no espaço. Isso porque essas iniciativas têm estado sujeitas a um forte processo de desmobilização, principalmente a partir de 2011, quando as ações de coordenação da REDTURS pela OIT foram encerradas, colocando em relevo a sua condição de informalidade, uma fragilidade para a sua consolidação. Entretanto, essa situação também vem provocando que as redes pesquisadas se articulem e se apoiem mutuamente para assegurar a continuidade das ações coletivamente programadas.

\section{Considerações finais}

O presente artigo buscou contribuir para a produção de reflexões sobre as iniciativas denominadas como turismo de base comunitária no contexto da América Latina. Para tal, essas foram interpretadas como um movimento liderado por determinados grupos sociais que vivem em situação de vulnerabilidade ambiental e à margem de megaprojetos turísticos convencionais. Com esse enfoque, no âmbito da REDTURS, 16 iniciativas de TBC de diferentes países da América Latina foram, preliminarmente, descritas e interpretadas, à luz do referencial teórico adotado sobre redes, a partir de três temas centrais de análise: o modo de organização das redes, o estabelecimento de alianças estratégicas e os meios de intercâmbio e compartilhamento de experiências intra e inter-redes.

As redes pesquisadas, pelo seu discurso, podem ser caracterizadas, predominantemente, como conjuntos de iniciativas envolvendo empreendimentos comunitários e familiares, associações de base local, cooperativas sociais, ONGs e agências e operadoras de viagens de 
TBC. Dessa forma, o seu modo de organização pode variar de acordo com os interesses individuais e/ou coletivos, que envolvem dimensões econômicas e políticas, com consequências diretas nas ações mobilizadas para a gestão das iniciativas de TBC em foco. Com esse enquadramento, a constituição desse tipo de redes tem sido dirigida às ações estratégicas voltadas, sobretudo, para a comercialização dos roteiros de TBC no mercado de viagens e turismo e para a gestão e a operacionalização dos empreendimentos comunitários. Por outro lado, nesse processo, também tem se efetivado o intercâmbio de experiências e o compartilhamento de recursos materiais e outros, como serviços, informações, conhecimentos e oportunidades para aprendizagem coletiva. Além disso, as redes pesquisadas buscam o fortalecimento das capacidades locais e a mobilização social para influenciar a formulação e a implementação de políticas públicas.

A interpretação dos discursos difundidos pelas redes de $T B C$ pesquisadas indica também ser a sua visão estratégica associada a duas perspectivas de ação distintas, porém interligadas. Sob a perspectiva endógena, busca-se a valorização do patrimônio natural e cultural, o respeito e a proteção aos territórios ancestrais, o desenvolvimento de capacidades organizativas, de cooperação entre os atores sociais para a facilitação da articulação em rede e de qualificação técnica e operacional em benefício das populações locais envolvidas diretamente com o TBC. Por outro lado, a partir de uma perspectiva exógena ao processo de formação de redes de $T B C$, busca-se desenvolver, também, a promoção de alianças com agentes externos, na tentativa de serem criadas alternativas para a inserção das propostas em desenvolvimento no mercado turístico e, ainda, para a influência no desenho de políticas públicas.

Tendo como base a articulação e as alianças estabelecidas com as organizações do movimento indígena e de comunidades tradicionais, as experiências autodenominadas como redes de TBC podem ser interpretadas, em seu conjunto, como um movimento que se constitui em estratégia de resistência ao turismo convencional e de articulação política para influir em políticas públicas. Nesse sentido, as redes de TBC podem, por pressuposto, envolver mecanismos de articulação social para o protagonismo comunitário, que implicam um processo dinâmico de mobilização/desmobilização dos atores sociais e também de mediação de conflitos. Além disso, algumas iniciativas pesquisadas utilizam estratégias de articulação para a organização e operacionalização comercial das ações em prol do $T B C$.

No que se refere, especificamente, ao estabelecimento de alianças para a construção de ações conjuntas, essa estratégia parece ser central para o planejamento turístico comunitário na América Latina. Isso porque a limitação de políticas públicas (capazes de fortalecer e/ou consolidar as iniciativas em curso) e de marcos normativos adequados para o desenvolvimento dessas redes, nos diversos países da região, tende a gerar dependência e subordinação às agências internacionais de fomento ao desenvolvimento ou outras instâncias de financiamento.

Mas, com relação ao estudo desenvolvido sobre esse tema, uma questão permanece em aberto para inspirar futuras reflexões: como ocorre a comunicação com as redes vizinhas? Essa questão se justifica porque, além da necessidade de se pensar a dinâmica de articulação de uma rede de TBC em si mesma, um desafio a ser superado, no futuro, para os projetos de TBC, é compreender as conexões entre as diversas redes com esse objetivo, considerando as suas propostas de atuação e o seu raio de alcance. Isso tende a ser um problema importante a ser enfrentado, tendo em vista, sobretudo, que o período de desarticulação da REDTURS pode contribuir para o enfraquecimento das redes locais.

Considerando o eixo de análise sobre as relações de intercâmbio e compartilhamento nas redes de $T B C$, parece claro, no discurso das experiências analisadas, que se busca promover um encontro entre os visitantes e a população anfitriã e também fortalecer o movimento de busca de diálogo com outras redes afins. De outra forma, são mencionados intercâmbios entre os atores sociais envolvidos que poderiam facilitar a captação de recursos financeiros, a difusão de informações e o conhecimento para outros membros das redes, além da aprendizagem coletiva e do fortalecimento das relações de colaboração e de solidariedade entre os atores sociais envolvidos. Assim, o reconhecimento desses intercâmbios de experiências parece representar uma estratégia para a articulação das redes de $T B C$, o que tende a indicar que esforços nessa direção devem ser valorizados. 
Portanto, a partir da interpretação dos discursos das experiências pesquisadas, da revisão bibliográfica e dos relatórios consultados, para que essas se consolidem, parece ser condição necessária a criação de espaços e instrumentos que fomentem, prioritariamente, a colaboração e o intercâmbio entre as iniciativas em curso, como fóruns. Esse esforço poderia potencializar a interação de empreendimentos de $T B C$ e a vivência de experiências de valor cultural em suas regiões de inserção, o que, por sua vez, poderia contribuir, em tese, para a tessitura e a articulação de ações multiescalares em rede.

Para se pensar o TBC em sua complexidade, parece ser ainda necessário considerar a noção de redes como um campo de forças, que não pode ser delineado apenas a partir de ações horizontais ou verticais na relação entre os atores sociais protagonistas do processo. Por essa razão, a noção de redes deve ser interpretada a partir de agenciamentos apreendidos como um movimento dinâmico de influência de um ator social sobre o outro, considerando que esses, em alguns momentos, aliam-se e fortalecem laços e acordos em comum e, em outros, opõem-se e redefinem interações sociais em contextos de disputa.

É importante ressaltar que, embora a noção de rede venha despertando interesse em reflexões teóricas e práticas, de diferentes campos do conhecimento, algumas limitações são ainda observadas na produção acadêmica sobre o tema, ainda incipiente no estudo de TBC.

Assim, seria importante aprofundar a investigação aqui realizada a partir da ampliação da pesquisa bibliográfica para casos estudados em outras áreas geográficas, assim como para o aprimoramento da metodologia adotada. Dessa maneira, seria possível mapear e interpretar, criticamente, um pluriverso de iniciativas de redes de TBC, problematizando melhor $\mathrm{o}(\mathrm{s})$ modo(s) de desenvolvimento do TBC na América Latina. Nesse caso, um desdobramento da presente pesquisa poderia ser a discussão sobre as implicações da parceria entre a sociedade civil, o poder público e o setor privado no contexto do TBC, considerando os vínculos que são produzidos e os efeitos das ações empreendidas entre os atores da rede. Além disso, poderiam ser analisadas possibilidades de definição de espaços estratégicos para a articulação entre os diversos atores envolvidos no TBC e interpretados os desafios e as alternativas para a integração regional na América Latina por essa via.

\section{Referências}

Apthapi. (2016). ¿Por qué APTHAPI? Red de Turismo Comunitario del Lago Titicaca. http://titicacaturismo.com/

Barbosa, L. M. (2011). Redes de Territórios Solidários do Turismo Comunitário: políticas para o desenvolvimento local no Ceará. Dissertação de Mestrado em Geografia. Fortaleza: Universidade Estadual do Ceará.

Bardin, I. (1994). Análise de conteúdo. Lisboa: Edições Setenta.

Bartholo, R.; Sansolo, D.; Bursztyn, I. (Orgs). (2009). Turismo de base comunitária: diversidade de olhares $e$ experiências brasileiras. Rio de Janeiro: Letra e Imagem.

Cabanilla, E.; Gentili, J. (2015). Características de las páginas de la internet de turismo comunitario en países de América. PASOS, 13 (1), 157-174.

Cañada, E. (2015). La comercialización del turismo comunitario en América Latina. Anuario de Estudios Centroamericanos, 41, 159-189.

Cooprena. (2016). Cooperative Consortium National Ecotourism Network, COOPRENA R.L. http://turismoruralcr.com/

Coriolano, L. N.; Sampaio, C. A. C. (2013). Territórios solidários de America Latina y turismo comunitario en rebote a los mega empreendimentos transnacional. Revista Iberoamericana de Turismo, 3 (1), 4-15.

Castelss, M. (2010). A sociedade em rede. São Paulo: Paz e Terra.

Costa, L.; Junqueira, V.; Martinho, C.; Fecuri, J. (Coords.). (2003). Redes: uma introdução às dinâmicas da conectividade e da auto-organização. Brasília: WWF-Brasil.

Gohn, M. (2010). Movimentos sociais e redes de mobilizações civis no Brasil contemporâneo. Petrópolis: Vozes.

Inostroza, V. G. (2008). Aportes para un modelo de gestión sostenible del turismo comunitario en la región andina. Gestión Turística, 10, 77-90.

Lang, M. (2016). Introdução: Alternativas ao desenvolvimento. In: Dilger, G.; Lang, M.; Pereira Filho, J. (Org.). Descolonizar o imaginário. Debates sobre pós-extrativismo e alternativas ao desenvolvimento. São Paulo: Fundação Rosa Luxemburgo, p. 25-44.

Latour, B. (2012). Reagregando o social: uma introdução à teoria do Ator-Rede. Salvador: Edufba.

Lomnitz, L. A. (2009). Redes sociais, cultura e poder. Rio de Janeiro: E-papers.

Krippendorf, J. (2002). Cartão Vermelho ao Turismo? Dez 
Princípios e desafios para um Desenvolvimento Sustentável do Turismo no Sec XXI. Oficina de Turismo. Rio Grande do Sul: Fórum Social Mundial.

Maldonado, C. (2010). Workshop planejamento e gestão de empreendimentos turísticos de base comunitária REDTURS. In: INOVABR, Inovação Social e Sustentabilidade. Rio de Janeiro: COPPE/ UFRJ, 22-26, Nov.

Maldonado, C. (2009). O turismo rural comunitário na América Latina: Gênesis, características e políticas. In: Bartholo, R.; Sansolo, D.; Bursztyn, I. (Orgs). Turismo de base comunitária: diversidade de olhares e experiências brasileiras. Rio de Janeiro: Letra e Imagem, p. 25-44.

Maldonado, C. (2007). Fortalecendo as Redes de Turismo Comunitário - REDTURS - na América Latina. Turismo Sustentável e Desenvolvimento Local. Turim, Itália: Centro Internacional de Formação da OIT, @local.glob, 4, 08-14.

Mielke, E.; Pegas, F. V. (2013). Turismo de base comunitária no Brasil: insustentabilidade é uma questão de gestão. Turismo em Análise, 24 (1), 170-189.

Meléndez, A. (2000). O Turismo na América Latina: situação atual e tendências. Turismo - Visão e Ação, 2 (5), 71-80.

Mendonça, T.; Irving, M. (2004). Turismo de base comunitária: a participação como prática no desenvolvimento de projetos turístico no Brasil Prainha do Canto Verde, Beberibe (CE). Caderno Virtual de Turismo, 4 (4), 12-22.

Neuhaus, E.; Silva, J. S. da (org). (2005). Um outro turismo é possivel! Reflexões sobre desigualdades, resistências e alternativas no desenvolvimento turístico. Fórum Social Mundial Porto Alegre 2005. Fortaleza: FBOMS/ Instituto Terramar.

OIT Organización Internacional Del Trabajo. (2008). Gobiernos locales, turismo comunitario y sus redes. Memoria V Encuentro consultivo regional (REDTURS). Ginebra: OIT, Documento de Trabajo n. 12.

OIT Organização Internacional do Trabalho. (1989). Convenção sobre Povos Indígenas e Tribais (No. 169). Geneva: OIT.

Panosso Netto, A. (2011). Filosofia do turismo: teoria e epistemologia. São Paulo: Aleph.

Parques para Chile. (2016). Inicio. http://www. parquesparachile.cl/

Pedro, R. (2008). Redes e controvérsias: ferramentas para uma cartografia da dinâmica psicossocial. In Anais do VII Esocite Jornadas Latino-Americanas de Estudos Sociais das Ciências e das Tecnologias. Rio de Janeiro: UFRJ.

Pedro, R. (2003). As redes na atualidade: refletindo sobre a produção de conhecimento. In: D'Ávila, M.; Pedro, R. (Org). Tecendo o desenvolvimento:
Saberes, Gênero, Ecologia Social. Rio de Janeiro: Mauad, p. 29-47.

Porto-Gonçalves, C. W. (2006). A reinvenção dos territórios: a experiência latino-americana e caribenha. In: Ceceña, A. E. (Coord.). Los desafíos de las emancipaciones en un contexto militarizado. Buenos Aires: CLACSO, p. 151-197.

Porto-Gonçalves, C. W.; Quental, P. de A. (2012). Colonialidade do poder e os desafios da integração regional na América Latina. Polis Revista Latinoamericana, 11(31), 295-332.

Raturc. (2016). http://raturc.desarrolloturistico.gov.ar/

Rethus. (2016). Rethus. http://www.puerta-yasuni. com/index.php?option $=$ com_content \&view $=\operatorname{article\& id}=14$

Red de Turismo Campesino. (2016). http:/www. turismocampesino.org/

Ricancie. (2016). Um poco de historia. http://ricancie2. nativeweb.org/es

Rita. (2016). Red indígena de turismo de México. http://www.rita.com.mx/

Runatupari. (2016). Our company. http://www. runatupari.com/

Redturs. (2016). Bienvenidos al Portal de las Culturas Vivas de América Latina. http://www.redturs.org/

Redturs. (2003). Declaración de San José sobre Turismo Rural Comunitario. San José de Costa Rica, el 28 de octubre 2003. Disponível em http://www.redturs. org/inicio/docu/ DeclaracionSan-Jose-Espa.pdf. Acesso em 22/04/2016.

Redturs. (2001). Declaración de Otavalo sobre Turismo Comunitario, sustentável, competitivo e com identidade cultural. Otavalo, Ecuador 14 de septiembre del 2001. Disponível em http://www. redturs.org/documentos/Otavalo.pdf. Acesso em 22/04/2016.

Sampaio, C., Zechner, T., Henríquez, C., Coriolano, L.; Fernandes, S. (2014). Turismo comunitário a partir de experiências brasileiras, chilenas e costarriquenhas. Revista Brasileira de Pesquisa em Turismo, 8(1), 42-58.

Sendasur. (2016). Quiénes somos. http://www. sendasur.com.mx/sitio/

Schlüter, R. G. (1994). El turismo en la periferia económica: el caso de América Latina. Papers de Turismo, 14(15): 149-161.

Tucum. (2016). https://www.facebook.com/ RedeTucumTurismoComunitario

Turisol. (2016). Sobre a Turisol. http://turisol.wix. com/redeturisol 
Tusoco. (2016). About Us. http://www.tusoco.com/

Vainer, C. B. (2006). Lugar, região, nação, mundo: explorações históricas do debate acerca das escalas da ação política. Revista Brasileira de Estudos Urbanos e Regionais, 8(2), 9-29.

Vasconcelos, E. (2002). Complexidade e Pesquisa Interdisciplinar. Petrópolis: Vozes.
Contribuição dos autores na construção do artigo MORAES: Elaboração do problema de pesquisa, dos procedimentos metodológicos e do referencial teórico; coleta, sistematização e análise de dados; construção da conclusão e organização da bibliografia.

IRVING: Orientação, redação e revisão do artigo.

MENDONÇA: Orientação, redação e revisão do artigo. 